\title{
Integration of a Commercial Barcode-Assisted Medication Dispensing System in a Teaching Hospital
}

\author{
Sarah Berdot ${ }^{1,2,3}$ Abdelali Boussadi ${ }^{2,4}$ Aurélie Vilfaillot ${ }^{5,6}$ Mathieu Depoisson ${ }^{1} \quad$ Claudine Guihaire $^{7}$ \\ Pierre Durieux ${ }^{2,4}$ Laetitia Minh Maï Le ${ }^{1,8}$ Brigitte Sabatier ${ }^{1,2}$
}

\footnotetext{
${ }^{1}$ Department of Pharmacy, Hôpital Européen Georges-Pompidou, Assistance Publique-Hôpitaux de Paris, Paris, France

2Equipe 22, Centre de Recherche des Cordeliers, UMR 1138 INSERM, Paris, France

${ }^{3}$ Department of Clinical Pharmacy, Faculty of Pharmacy, EA EA4123, Université Paris Sud, Châtenay-Malabry, France

${ }^{4}$ Département de Santé Publique et Informatique Médicale, Hôpital Européen Georges-Pompidou, Assistance Publique-Hôpitaux de Paris, Paris, France

5 Unité de Recherche Clinique, Hôpital Européen Georges-Pompidou, Assistance Publique-Hôpitaux de Paris, Paris, France

${ }^{6}$ INSERM, Centre d'Investigation Clinique 1418 (CIC1418), Paris, France

${ }^{7}$ Hospital Nursing staff (DSAP), Hôpital Européen Georges-Pompidou, Assistance Publique-Hôpitaux de Paris, Paris, France

8 Lip(Sys)2, EA7357, UFR Pharmacie, U-Psud, Université Paris-Saclay, Paris, France
}

Appl Clin Inform 2019;10:615-624.
Address for correspondence Sarah Berdot, PharmD, PhD, Department of Pharmacy, Hôpital Européen Georges-Pompidou, 20 rue Leblanc, 75015 Paris, France (e-mail: sarah.berdot@aphp.fr).

\section{Abstract}

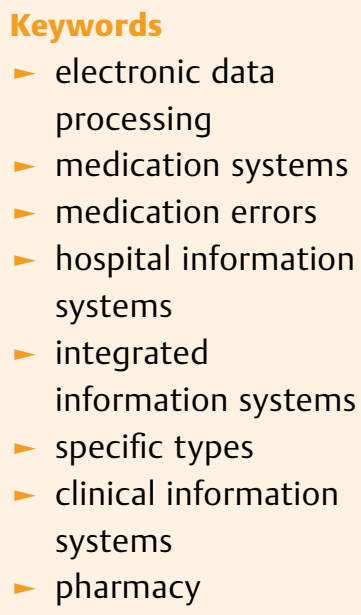

Objectives A commercial barcode-assisted medication administration (BCMA) system was integrated to secure the medication process and particularly the dispensing stage by technicians and the administration stage with nurses. We aimed to assess the impact of this system on medication dispensing errors and barriers encountered during integration process.

Methods We conducted a controlled randomized study in a teaching hospital, during dispensing process at the pharmacy department. Four wards were randomized in the experimental group and control group, with two wards using the system during 3 days with dedicated pharmacy technicians. The system was a closed loop system without information return to the computerized physician order entry system. The two dedicated technicians had a 1-week training session. Observations were performed by one observer among the four potential observers previously trained. The main outcomes assessed were dispensing error rates and the identification of barriers encountered to expose lessons learned from this study.

Results There was no difference between the dispensing error rate of the control and experimental groups ( $7.9 \%$ for both, $p=0.927)$. We identified 10 barriers to pharmacy barcode-assisted system technology deployment. They concerned technical (problems with semantic interoperability interfaces, bad user interface, false errors generated, lack of barcodes), structural (poor integration with local information technology), work force (short staff training period, insufficient workforce), and strategic issues (system performance problems, insufficient budget). received

March 23, 2019

accepted after revision June 30, 2019
(C) 2019 Georg Thieme Verlag KG Stuttgart · New York
DOI https://doi.org/ $10.1055 / \mathrm{s}-0039-1694749$. ISSN 1869-0327. 
Conclusion This study highlights the difficulties encountered in integrating a commercial system in current hospital information systems. Several issues need to be taken into consideration before the integration of a commercial barcode-assisted system in a teaching hospital. In our experience, interoperability of this system with the electronic health record is the key for the success of this process with an entire closed loop system from prescription to administration. BCMA system at the dispensing process remains essential to purchase securing medication administration process.

\section{Background and Significance}

The median medication administration error rate can reach almost $20 \%$, including wrong-time errors, and $10 \%$ without wrong-time errors. ${ }^{1,2}$ Barcode-assisted medication administration (BCMA) systems are developed ${ }^{3}$ and are reliable to secure administration process. In a systematic review, Keers et al identified error-provoking conditions that influence administration errors. ${ }^{4}$ The authors found that administration errors appeared to be associated with errors that occurred earlier in the medication process, during pharmacy dispensing, and ward stock management. ${ }^{5,6}$ A dispensing error is one made by pharmacy staff when distributing medications to nursing wards or directly to patients in an ambulatory care pharmacy. ${ }^{7}$ Cina et al evaluated the dispensing process in a U.S. hospital for 7 months. Error rates reached $3.6 \%$, before verification by the pharmacist, and decreased to $0.75 \%$ after pharmacist control, with approximately $23.5 \%$ of undetected errors resulting in potential adverse drug events if they reached the patient. ${ }^{6}$ In the MEDMARX program, $21.6 \%$ of records concerned dispensing errors in $2002 .^{8}$ According to the French national declarative study conducted from 2005 to $2009,{ }^{9}$ these errors concerned $15.7 \%$ of voluntary reports.

Many actions have been investigated to secure the medication process, including pharmacy informatics, pharmaceutical analysis, unit-dose dispensing, robotics, and automated dispensing cabinets, as well as BCMA and dispensing systems. ${ }^{10,11}$ By verifying compliance with the 5-rights rule (the right drug to the right patient at the right dose by the right route and at the right time), barcode-assisted technologies help to prevent medication-administration errors, as stated by the Joint Commission on Accreditation of Healthcare Organizations (Joint Commission) in the early 2000s. Barcode system also offers an interesting alternative to extend safety to the appropriate documentation by increasing the dispensing and administration traceability, as described in Anglo Saxons countries in the 6 -rights rule. However, adoption of these systems has been slow: $1.5 \%$ of North American hospitals in 2002 were equipped with barcode-assisted technology ${ }^{12}$; whereas $83.3 \%$ of hospitals with more than 600 beds were using this system to administer medications by $2013 .{ }^{10}$ By $2016,92.6 \%$ of hospitals, overall, had BCMA systems to verify patient identity and electronically verify the doses administered by nurses. ${ }^{13}$

In addition to the administration process, barcode-assisted technologies present substantial advantages for drug management and dispensing. However, these systems are rarely used in the pharmacy. Poon et $\mathrm{al}^{14}$ reported a decrease in dispensing errors after implementation of barcode-assisted dispensing system. However, they found that the efficacy of such systems depended on their configuration, as they studied configurations that scanned all drug doses or only one per batch. They also highlighted the dangers of overreliance on technology and the existence of workarounds.

Following these considerations, we integrated a commercial BCMA system to secure the medication process in our hospital information system (HIS). Before integration to the unit cares, the BCMA system was tested at the hospital facility and more particularly applied at the dispensing step.

\section{Objectives}

Consequently this study aimed to assess the impact of a commercial BCMA system on medication errors during the dispensing stage by technicians and assess barriers encountered during the integration process.

\section{Methods}

\section{Setting}

The study was conducted in the pharmacy department at a teaching hospital (European Georges-Pompidou Hospital, HEGP) in Paris, France (714 beds and 106 day-hospital seats). The hospital is equipped with a patient information system integrating an electronic health record (EHR) and a computerized physician order entry system (CPOE) (DxCare, Medasys). Electronic prescriptions are available for all clinical wards, except intensive care units. Each electronic prescription is validated by a pharmacist. Each day, pharmacy technicians refill automated medication dispensing cabinets (Omnicell Inc.) available in each ward $(n=43)$. The first doses and the "as needed" doses are taken from the cabinet by nurses. The next day, drugs are manually dispensed on a unit-dose basis for four clinical wards and by global deliveries for other wards. For the four unitdose dispensing wards, four dedicated pharmacy technicians manually deliver drugs to each ward, each day, in pill boxes. A second pharmacy technician verifies the accuracy of the medications filled by the first technician before delivery to the ward under a pharmacist's supervision. Approximately 3.5 million doses of medication are dispensed per year from the central inpatient pharmacy.

We investigated a commercial BCMA technology to improve the safety of our medication process. The DREAM protocol 
(number PHRQ1034 [DGOS 2012]) was a major initiative between the pharmacy and nursing staff leaders, evaluating the use of the BCMA system to decrease administration errors. The first step was to qualify the system at the pharmacy department for barcode-assisted medication dispensing before its implementation. All data were studied anonymously and no error reached the patient as the observers made a final control with drugs adjustments before delivering to the clinical ward.

\section{Intervention}

The intervention consists of the use of a commercial BCMA technology system called to control medication dispensing. The system was a closed loop BCMA as it was linked to the CPOE but without information return from the BCMA system to the CPOE as described in - Supplementary Material A (available in the online version).

\section{Study design}

The study was a randomized controlled study and was conducted during 6 days in May 2016. The four unit-dose dispensing wards ( 90 beds, - Table 1 ) were included in this study: one surgical ward (cardiovascular surgical) and three specialist area (immunology-cardiology, vascular medical, and nephrology).

Each day, the four unit-dose dispensing wards were prepared simultaneously by pharmacy technicians. Each ward was in a first time, prepared by a dedicated technician, and in a second time, controlled by an observer who was different from technicians.

At the beginning of the study, two wards (cardiovascular surgical and immunology-cardiology as described in -Table 1) were randomized into the experimental group using a list of random numbers. Due to technical limitation (one machine equipped with BCMA system available on site) and time consuming, only two wards were observed each day: one ward of the experimental group and one of the three other wards selected using a list of random numbers generated with excel as the control group ( - Table 1 ).

Each experimental ward was evaluated during 3 days. Depending on the randomization, an experimental ward could serve as a control ward (as, for example, cardiovascular surgical ward served as experimental group on day 1 and on control group on day 5). Technicians dedicated to the two experimental wards had a 1-week training session given by a

Table 1 Design of the study with type of ward

\begin{tabular}{|l|l|l|}
\hline Day & Experimental group & Control group \\
\hline D1 & Cardiovascular surgical & Immunology-cardiology \\
\hline D2 & Cardiovascular surgical & Vascular medical \\
\hline D3 & Cardiovascular surgical & Nephrology \\
\hline D4 & Immunology-cardiology & Vascular medical \\
\hline D5 & Immunology-cardiology & Cardiovascular surgical \\
\hline D6 & Immunology-cardiology & Nephrology \\
\hline
\end{tabular}

senior pharmacy technician and two senior pharmacists (S.B., L.L.) prior to implementation.

\section{Observation}

We used a technique derived from direct observation. ${ }^{7,15,16}$ Observations were performed by one observer among the four potential observers previously trained (by the senior pharmacy technician in an internal training) including a senior pharmacy technician, a senior pharmacy technician manager, and two senior pharmacists (S.B., L.L.).

Interrater reliability of the four observers was studied using the Fleiss kappa coefficient. ${ }^{17}$ The observers checked the compliance of drugs prepared by technicians with drugs prescribed by the physician that should have been prepared as described in -Fig. 1. They did not observe directly the technician while preparing the orders. Observers used the same data collection sheet to collect: the date and the time of the observation, the ward observed, and potential dispensing errors related to the name of the drug, dose, dosage form, administration route, time, deteriorated drug, and additional information needing for drug identification more particularly for dose introduce in package with radiofrequency identification (RFID) (drug label, batch, expiry date, and number of tablets on the package). For each divergence, the observer immediately verified on the BCMA system the drug to be dispensed to establish the source of the error (BCMA system or human error). At the start of the observation period, each of the four technicians gave consent for observation of their preparation by the observers.

For each error detected by the observer, the preparation was modified before dispensing to the clinical ward.

\section{Outcomes}

The main outcomes assessed were dispensing error rates and the identification of barriers encountered to expose lessons learned from this study. Any discrepancy between preparation and prescription was noted by observer and analyzed by two senior pharmacists (S.B., L.L.). The errors detected were then classified in types of errors. The error rates were calculated as the number of dispensing errors over the total opportunities for errors (TOE), which is the sum of all doses ordered, plus all unordered doses prepared, ${ }^{18}$ multiplied by 100. Drug dispensing errors were classified into 10 categories derived from the American Society of Health-System Pharmacists classification ${ }^{19}$ : omission error (failure to prepare an ordered dose to a patient), wrong-time error (preparation of a drug for the wrong day, or preparation of a drug that is suspended), unordered drug error, wrong patient, wrong drug, wrong-dose error, wrong-dosage-form error, wrong route (different from the route prescribed), deteriorated drug error (use of expired or improperly stored drugs), and other medication errors (including any drug-dispensing errors not fitting into the above predefined categories, such as default of drug labeling on the bag, drug integrity, batch number, and expiry date).

Errors were immediately analyzed for the experimental group by the observer by comparing prescribed drugs and drugs proposed by the BCMA system to evaluate its cause, 
Who is concerned?

Experimental group

Physician

Pharmacy technician

Observer

Observer

Local informatics engineer team

Observer

Pharmacy technician

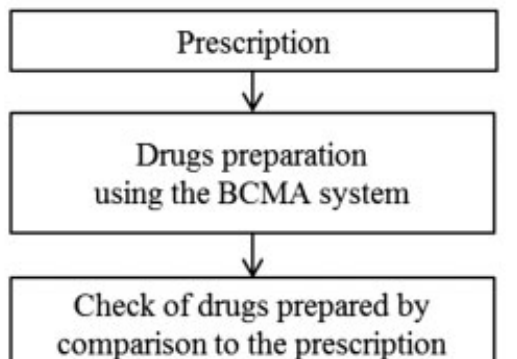

comparison to the prescription

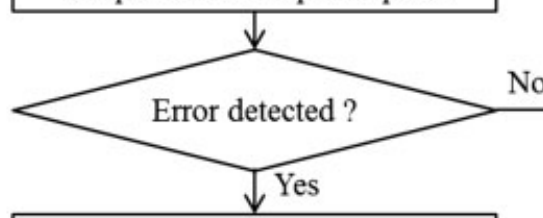

Verification of the order indicated on the BCMA system

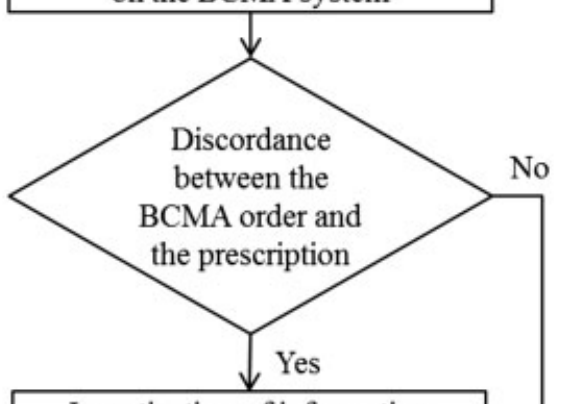

\section{Investigation of information}

flaws

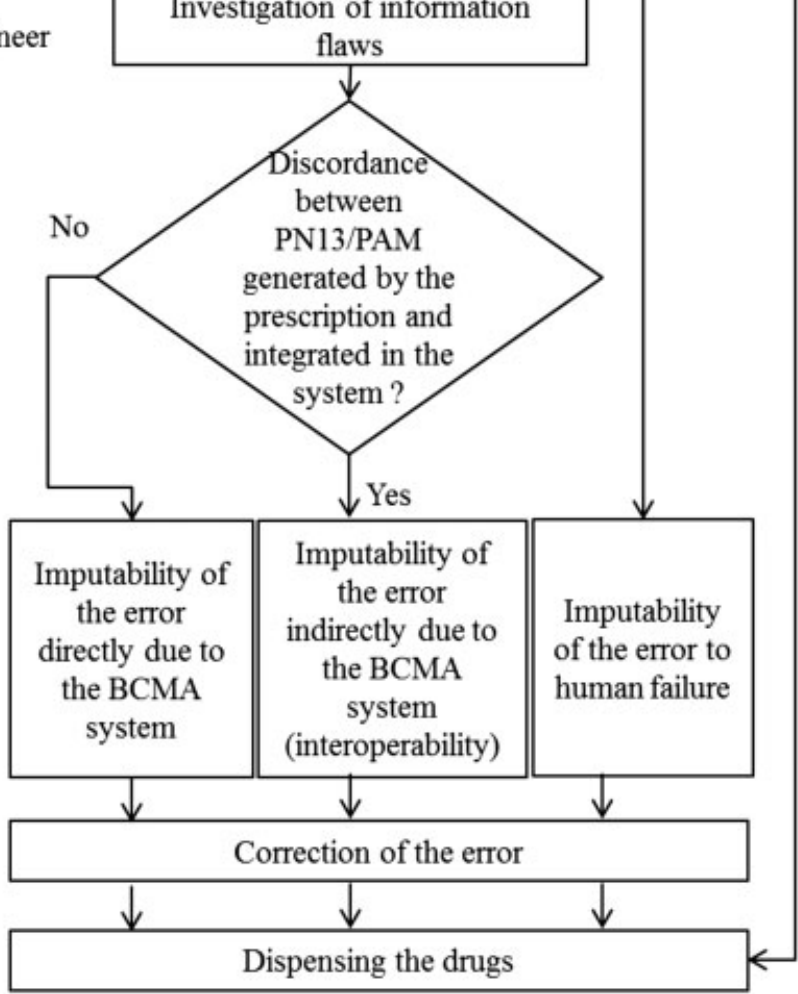

Control group
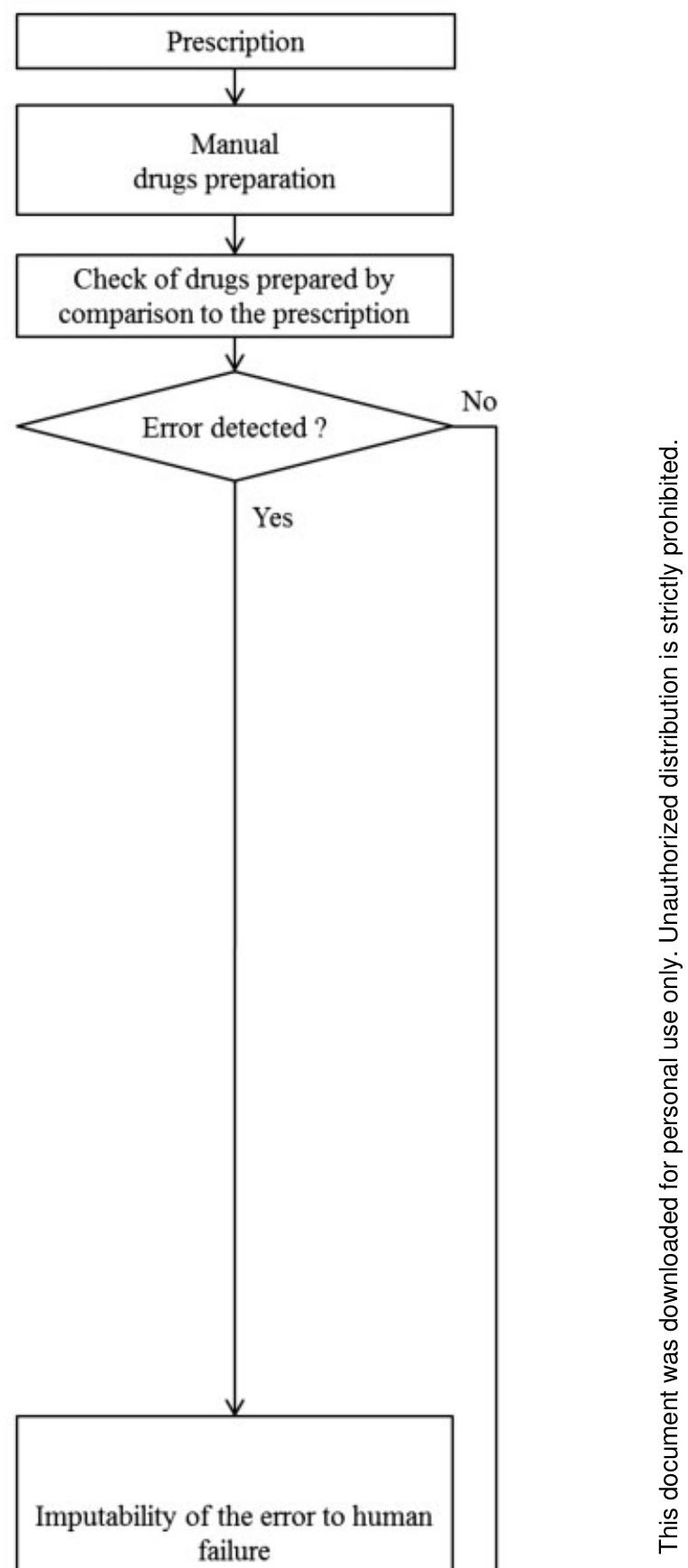

Fig. 1 Workflow diagram for identification errors in the experimental group (using barcode-assisted medication administration [BCMA] dispensing system) and the control group (manual dispensing) and its causes. 
each type of error can be caused by humans, the BCMA system (directly or indirectly), or both.

After observations, all observed dispensing errors and dysfunctions were analyzed by a multidisciplinary team to identify their causes and list the lessons learned from this project. The team was composed of experts in the medication process: a local informatics engineer in charge of the project (A.B.), a physician expert in methodology (P.D.), and three senior pharmacists (B.S., S.B., L.L.). We matched these issues with the technology-related challenges in supporting optimal pharmacy practice models in hospitals and health systems defined by Siska and Tribble ${ }^{20}$ : financial, work force, strategic, cultural, structural, technical, privacy, and security issues.

\section{Statistical Analysis}

Categorical variables are reported as frequencies (percentages) and numerical variables as medians (minimum and maximum). Error rates between the two groups were compared using chi-square and Fisher tests. We investigated the relationship between the occurrence of errors (error rate) and potential risk factors (drug Anatomical Therapeutic Chemical [ATC] classification, drug administration route, TOE), using logistic regression models with random effects (intercepts) for multiple observations. All risk factors were analyzed by univariate and multivariate analyses if factors were significant at the 5\% level. Results are expressed as odds ratios (ORs), with the 95\% confidence intervals (CIs). Data were analyzed with SAS version 9.4 (SAS Institute, Cary, North Carolina, United States). A preliminary study (data not published) during 5 days per ward (four wards) showed a dispensing error rate of $4.3 \%$ (2,537 TOE). Poon et $\mathrm{al}^{14}$ reported a $85 \%$ relative reduction in the rate of target dispensing errors and a $36 \%$ relative reduction in the rate of all dispensing errors. To detect a difference of $88 \%$ with a power of $80 \%$, the TOE was estimated to 700 . Observation period was fixed to 3 days per ward for the intervention group.

\section{Ethics}

This study was conducted as part of the protocol DREAM (NCT02325336). Human research ethics approval was received from CPP-Ile-de-France in November 2013 (ID RCB: 2013A01101-44). The first step was to qualify the system at the pharmacy department for barcode-assisted medication dispensing before its implementation. All data were studied anonymously and no error reached the patient as the observers made a final control with drugs adjustments before delivering to the clinical ward. All pharmacy technicians gave their consent for the study.

\section{Results}

\section{Impact on Dispensing Errors}

Overall, 1,424 TOE for 112 patients were observed. The four dedicated pharmacy technicians were observed. The average age was 38 years (32-43) with 6.2 years of mean experience in unit-dose dispensing ( 3 months-14 years). The Fleiss kappa coefficient for evaluation of interrater reliability of the four observers was 0.877 (standard deviation: 0.037). The global dispensing error rate was 7.9\% (59 errors/750 TOE) and 7.9\%
Table 2 Types of dispensing errors in the control and experimental groups

\begin{tabular}{|l|l|l|l|}
\hline Type of error & $\begin{array}{l}\text { Control } \\
\text { group } \\
\boldsymbol{n}(\%)\end{array}$ & $\begin{array}{l}\text { Experimental } \\
\text { group } \\
\boldsymbol{n}(\%)\end{array}$ & $p$-Value \\
\hline Omission & $4(0.5)$ & $22(3.3)$ & $<0.001$ \\
\hline Wrong-time & $2(0.3)$ & $0(0.0)$ & 0.277 \\
\hline Wrong patient & $8(1.1)$ & $0(0.0)$ & 0.006 \\
\hline Unordered drug & $9(1.2)$ & $1(0.2)$ & 0.016 \\
\hline Wrong drug & $0(0.0)$ & $0(0.0)$ & - \\
\hline Wrong dose & $22(2.9)$ & $24(3.6)$ & 0.504 \\
\hline Wrong route & $0(0.0)$ & $1(0.2)$ & 0.473 \\
\hline Deteriorated drug & $0(0.0)$ & $0(0.0)$ & - \\
\hline $\begin{array}{l}\text { Other } \\
\text { medication } \\
\text { errors }\end{array}$ & $14(1.9)$ & $5(0.7)$ & 0.065 \\
\hline Total & & & \\
\hline
\end{tabular}

(53 errors/674 TOE) for the control and experimental groups, respectively. The difference of the global dispensing error rate between the two groups was not significant $(p=0.927, \mathrm{OR}=1$ [95\% CI: 0.679-1.471]), whereas there were significant differences in the types of errors ( - Table 2). Thus, the omission error rate was significantly higher in the experimental group $(p<0.001)$, whereas there were significantly fewer wrong patient $(p=0.006)$ and unordered-drug errors $(p=0.016)$. Other medication errors were no information on the number of tablets on the package ( $n=4$ in the experimental group, $n=$ 14 in the control group) and a drug-label error ( $n=1$ in the experimental group). There were no wrong dosage-form errors. Univariate logistic regression analysis showed that the occurrence of errors was not significantly associated with drug ATC classification, drug administration route, or TOE (- Supplementary Material B, available in the online version). Thus, multivariate analysis was not performed.

Among the 53 errors in the experimental group, 33 (62.3\%) were due to human and 20 (37.7\%) were directly or indirectly due to the BCMA system. Type of errors due to human were mainly wrong dose $(n=21,39.6 \%)$, omission $(n=6,11.3 \%)$, other medication $(n=5,9.4 \%)$, and wrongroute errors ( $n=1,1.9 \%)$. Type of errors due to the BCMA system were mainly omission ( $n=16,30.2 \%)$, wrong dose ( $n=3,5.7 \%)$, and unordered-drug errors $(n=1,1.9 \%)$.

\section{Barriers Identified}

We identified 10 barriers to commercial pharmacy BCMA system technology deployment and use at our hospital (-Table 3).

We encountered several technical barriers ( - Table 3, barriers 1-5) during the deployment and assessment steps of this study. Analysis of the log files showed that issues number 1 and 2 were related to interoperability between the various components of the architecture deployed. These issues had an impact on the final version of the deployment architecture of the BCMA system (- Supplementary Fig. S1, available in the online 
Table 3 List of barriers to the deployment and the use of a BCMA system identified during the assessment study by the expert committee

\begin{tabular}{|c|c|c|c|c|}
\hline Number & Scope & Barriers/errors & Illustration & Lessons learned \\
\hline 1 & Technical & $\begin{array}{l}\text { Outdated architecture } \\
\text { for the semantic } \\
\text { interoperability } \\
\text { interfaces of the local } \\
\text { hospital information } \\
\text { system (HIS) }\end{array}$ & $\begin{array}{l}\text { The interoperability } \\
\text { interfaces used during this } \\
\text { study were based on files } \\
\text { generated by database } \\
\text { triggers. These files } \\
\text { contain the data required } \\
\text { elements, structured } \\
\text { according to the } \\
\text { corresponding standard. } \\
\text { In our opinion, file-based } \\
\text { interoperability interfaces } \\
\text { should be, avoided, } \\
\text { because the generated } \\
\text { files necessitated } \\
\text { management of the disk } \\
\text { space in which files are } \\
\text { stored. In addition, files } \\
\text { can be lost, deleted, or } \\
\text { corrupted }\end{array}$ & $\begin{array}{l}\text { Favor Web } \\
\text { service-based semantic } \\
\text { interoperability } \\
\text { interfaces at the local } \\
\text { HIS }^{24}\end{array}$ \\
\hline 2 & Technical & $\begin{array}{l}\text { The BCMA system did } \\
\text { not have a semantic } \\
\text { interoperability layer } \\
\text { already implemented }\end{array}$ & $\begin{array}{l}\text { The vendor delivered the } \\
\text { BCMA system without an } \\
\text { interoperability layer. This } \\
\text { layer was developed } \\
\text { during the study by a } \\
\text { senior development } \\
\text { engineer working for the } \\
\text { vendor and paid by the } \\
\text { project }\end{array}$ & $\begin{array}{l}\text { Pay attention to the } \\
\text { contract and the } \\
\text { required specifications } \\
\text { during the first steps of } \\
\text { the project }\end{array}$ \\
\hline 3 & Technical & Bad user interface & $\begin{array}{l}\text { Users complained of the } \\
\text { number of clicks required } \\
\text { to prepare a medication } \\
\text { prescription }\end{array}$ & $\begin{array}{l}\text { Favor the involvement } \\
\text { of pharmacy } \\
\text { technicians and nurses } \\
\text { during the implemen- } \\
\text { tation process: need } \\
\text { agile software develop- } \\
\text { ment processes. } 34 \\
\text { Include human factor } \\
\text { engineering principles }\end{array}$ \\
\hline 4 & Technical & False errors & $\begin{array}{l}\text { The system did not have } \\
\text { interoperability to convert } \\
\text { drug dosage to the sum of } \\
\text { multiple drug units with } \\
\text { different dosages. } \\
\text { Example: vancomycin } 1 \mathrm{~g} \\
\text { prescribed; vancomycin } \\
250 \mathrm{mg}+750 \mathrm{mg} \\
\text { dispensed and scanned. } \\
\text { False error detected by the } \\
\text { system because it did not } \\
\text { sum the two doses, but, in } \\
\text { fact, there was no error, as } \\
\text { the sum of the two doses } \\
\text { was correct }\end{array}$ & $\begin{array}{l}\text { Favor interoperability } \\
\text { prescription and } \\
\text { dispensing for drug } \\
\text { dosage (example: use } \\
\text { of an interoperability } \\
\text { system between the } \\
\text { prescription and } \\
\text { dispensing stages) }\end{array}$ \\
\hline 5 & $\begin{array}{l}\text { Technical/ } \\
\text { Structural }\end{array}$ & $\begin{array}{l}\text { Problem with the } \\
\text { scanning of drug } \\
\text { barcodes }\end{array}$ & $\begin{array}{l}\text { Lack of unit-dose, includ- } \\
\text { ing barcode or datamatrix, } \\
\text { at the unit level to simplify } \\
\text { unit-dose dispensing }\end{array}$ & $\begin{array}{l}\text { Favor the use of drug } \\
\text { unit-doses with } \\
\text { datamatrix }\end{array}$ \\
\hline 6 & Structural & $\begin{array}{l}\text { Bad or inexistent } \\
\text { relationship with } \\
\text { local IT }\end{array}$ & $\begin{array}{l}\text { Several members of the IT } \\
\text { staff were not aware of the } \\
\text { project due to poor } \\
\text { communication }\end{array}$ & $\begin{array}{l}\text { Make the project part of } \\
\text { the strategic plan of the } \\
\text { IT department }\end{array}$ \\
\hline
\end{tabular}


Table 3 (Continued)

\begin{tabular}{|c|c|c|c|c|}
\hline Number & Scope & Barriers/errors & Illustration & Lessons learned \\
\hline 7 & Workforce & $\begin{array}{l}\text { Short staff training } \\
\text { period }\end{array}$ & $\begin{array}{l}\text { We observed dispensing } \\
\text { errors due to human error, } \\
\text { associated with misuse of } \\
\text { the system, despite a } \\
\text { 1-week training period }\end{array}$ & $\begin{array}{l}\text { Plan multiple tests and } \\
\text { training sessions with } \\
\text { accreditation }\end{array}$ \\
\hline 8 & Workforce & Insufficient workforce & $\begin{array}{l}\text { Only one full-time equiva- } \\
\text { lent (the development } \\
\text { engineer of the vendor) was } \\
\text { intermittently involved } \\
\text { during the study and was } \\
\text { not based at the hospital }\end{array}$ & $\begin{array}{l}\text { Pay attention to the } \\
\text { contract and the } \\
\text { required specifications } \\
\text { during the first steps of } \\
\text { the project }\end{array}$ \\
\hline 9 & Strategic & $\begin{array}{l}\text { Problem with perfor- } \\
\text { mance of the system }\end{array}$ & $\begin{array}{l}\text { The performance of the } \\
\text { system for a teaching } \\
\text { hospital, with continuous } \\
\text { data concerning prescrip- } \\
\text { tion (PN13), was not } \\
\text { sufficient, as it was initially } \\
\text { developed for retirement } \\
\text { homes }\end{array}$ & $\begin{array}{l}\text { Pay attention to the } \\
\text { experience of the } \\
\text { vendor with IT imple- } \\
\text { mentation in a teaching } \\
\text { hospital setting }\end{array}$ \\
\hline 10 & Strategic & Insufficient budget & $\begin{array}{l}\text { There were no full-time } \\
\text { permanent engineers, } \\
\text { they changed during the } \\
\text { development phase, and } \\
\text { there was not enough } \\
\text { budget to recruit full-time } \\
\text { permanent staff }\end{array}$ & $\begin{array}{l}\text { Use estimation and cost } \\
\text { methods (COCOMO II, } \\
\text { The Constructive Cost } \\
\text { Model }^{35} \text { ) to better } \\
\text { assess the project } \\
\text { budget }\end{array}$ \\
\hline
\end{tabular}

Abbreviations: BCMA, barcode-assisted medication administration; IT, information technology.

version) and the final assessment results. To access EHR/CPOE data on medication prescriptions, the BCMA system was connected to a set of file-based interoperability interfaces using the PN13 standard which is the commonly used standard for drug data exchanges in the French hospitals. ${ }^{21}$ To access EHR/ CPOE data on patient movements, the BCMA system was initially connected to a set of file-based interoperability interfaces using the Health Level Seven Patient Administration Management (PAM) standard. However, the latter interface generated several errors during integration tests, mainly because interoperability files were lost or incomplete. We finally connected the BCMA system directly to a duplicate database of the EHR/CPOE to avoid disturbing the database in production, as described in - Supplementary Fig. S2 (available in the online version). During the assessment study, the process of data duplication of the EHR/CPOE database experienced several periods of desynchronization. During these periods, the data on patient movements and identification were not analyzed in a timely manner by the BCMA system. Barrier number 3 is related to the user interface (UI) of the BCMA system. The time and number of clicks needed to finalize the process of preparing a medication prescription was judged to be high by the pharmacy-technician users. Several of these clicks and window transitions were unnecessary. The UI of the BCMA system was not adapted to the context of our hospital, as the initial UI design of the system was for retirement homes. Barrier number 4 was the lack of a system or functionalities allowing to convert drug dosages scanned to a standard format and to get the sum. In France, manufacturers have been obliged to put barcodes on drug packages since 2011, but barcodes are rarely used at the unit-dose level, constituting barrier number 5. Indeed, even if barcodes were provided at the unit-dose level, they could barely be scanned, due to reflective surfaces or mapping to incorrect products that were not recognized by the product database. We put the unit-dose drug in small bags with a RFID tag inside, summarizing the drug information, to overcome this barrier. Concerning structural issues (barrier number 6), the hospital information technology (IT) staff was not sufficiently informed of the project to help during its development. Concerning the work force, training in the use of the system was insufficient (barrier number 7). The pharmacy technicians were trained for 1 week on the use of the system, which was originally evaluated to be sufficient. However, we observed some human errors in the experimental group, showing a lack of sufficient training. Barrier number 8 concerned the involvement of the computer science engineer who was in charge of connecting the BCMA system to the local HIS. The engineer was not a full-time employee and was not based at our hospital. Finally, there were two barriers concerning strategic issues (barriers number 9 and 10). The performance of the system in daily routine care of a teaching hospital was overestimated, whereas the costs generated by implementation of the system were underestimated.

\section{Discussion}

Before using the BCMA system at administration stage by nurses, we investigated the use of the BCMA technology in 
the pharmacy department of a teaching hospital during the dispensing process. Dispensing error rates between manual dispensing and that assisted by barcode-assisted technology were not significantly different (7.9\% for both). Wrong-dose errors were the most frequently observed during the study in both groups ( 2.9 and 3.6\%, respectively). However, we observed no wrong patient and only one unordered drug error with the BCMA system, as expected. For other errors (i.e., lack of number of tablets listed or drug label errors on the package manually identified by the pharmacy technician), complementary approaches should be explored, because BCMA technology is not designed to improve these types of errors.

Conflicting data on the impact of BCMA systems on dispensing errors is reported in the literature. Poon et al assessed whether implementation of barcode technology reduced dispensing errors and potential adverse drug events. They found a decrease of all dispensing errors from $0.88 \%$ during the prebarcode period to $0.57 \%$ in the post-barcode period. ${ }^{14}$ These results represent a $36 \%$ relative reduction in the rate of all dispensing errors. Relative reductions in wrong medication, wrong dose, and expired medication errors were observed, but a significant increase in incorrect labels was detected. Conversely, Samaranayake et $\mathrm{al}^{22}$ also assessed the effect of a BCMA system, used without the support of computerized prescribing (standalone BCMA), on the dispensing process and its users. They found that the potential dispensing error rates increased significantly after implementation of the system from $0.4 \%(12 / 2,828 \mathrm{TOE})$ to $3.2 \%$ (15/471 TOE). We observed the same tendency in our study: there were more omission errors after implementation (one error before vs. eight errors after). The other errors observed after implementation were wrong patient $(n=1)$, wrong frequency $(n=1)$, information missing from the label $(n=1)$, and procedural errors $(n=4)$, whereas no wrong-dose or wrong-dosage errors were observed before implementation.

As described by Koppel et al, ${ }^{23}$ new error sources were observed using the BCMA system as assumed, dose information or duplicative medication. Semantic interoperability between the BCMA system and other components of the local HIS was a major issue ( - Table 3 ), resulting in most of the BCMA system errors. Omission errors attributed to the BCMA system were mainly due to two types of issues: (1) failure in generating PN13 files by the interoperability interfaces deployed between the BCMA system and the EHR/CPOE system and (2) failure in generating PAM files by the interoperability interfaces deployed between the BCMA system and the EHR/CPOE system. During the assessment study, the BCMA system was connected to a duplicate database of the EHR/CPOE to avoid disturbing the database in production. Failure in generating PAM files was due to periods of data desynchronization between the EHR/CPOE duplicate database and the EHR/CPOE database in production. Specifications of the interoperability interfaces of the BCMA system should be discussed during determination of the system specifications with the vendor. The system should be delivered as a "plug and play" system, and if further development is required, the vendor should provide it before the assessment study starts. Concerning the local HIS, inter- operability interfaces should be based on Web services or Representational State Transfer architectures, as promoted by recent interoperability standards. ${ }^{24}$ HIS managers would benefit from including a dedicated interoperability IT engineer in their work force, as issues related to interoperability are current in the daily life of a modern hospital.

Human factor engineering (HFE) principles should be included in the implementation of current clinical information systems. Saleem et $\mathrm{al}^{25}$ claimed that the UI is the last, but not least important, barrier between current knowledge concerning the assessment of clinical information systems and their expected outcomes in enhancing patient safety. Few studies have addressed HFE principles in the design of clinical information systems. ${ }^{26}$ Phansalkar et $\mathrm{al}^{27}$ reviewed the literature to provide recommendations for better integration of HFE principles in the implementation of medication safety alerts in clinical information systems. The results of this study have been used by Zachariah et $\mathrm{al}^{26}$ to propose a "turnkey" tool to assess HFE principles of drug-drug interaction alerts. This tool may assist institutions in the implementation of homemade systems and/or in selecting a suitable medication-related decision support vendor product.

Electronic barcode scanning constitutes an opportunity for improving traceability of medicinal products throughout the health care chain but also reduces the use of falsified medicines. However, barcodes were not systematically present at the drug unit level. As required by European Union regulations, only human-readable format (printed as letters and numbers) and linear barcodes which do not encode variable or dynamic data such as batch numbers and expiry dates were available on both the primary and secondary product package levels. Thus, we put the unit-doses in bags with a RFID tag which was time consuming. Human errors observed in the study showed misuse of the system. To facilitate the routine electronic recording of dynamic product information, the use of unit-doses with two-dimensional (2D) barcodes as the 2D datamatrix which have the technical ability to encode dynamic data needing to secure the full track-and-trace system have to be preferred. ${ }^{28}$ According to the pharmacy technicians' feedback, we recommend a longer training period to acquire the necessary skills to use the system, that should be objectified by accreditation and multiple user tests before implementation.

Despite widespread implementation of BCMA technology in clinical wards to secure drug administration, ${ }^{13}$ it is little used by central pharmacies. Numerous barriers to explain its lack of use are reported in the literature. Our results are consistent with the barriers and recommendations reported by Nanji et al for the implementation of BCMA systems. ${ }^{29}$ They identified three major potential obstacles to implementation of barcode-assisted technology at pharmacies, concerning the technology, the process (with the training of users and the workflow redesign), and staff resistance. Concerning staff resistance, we communicated regularly with the pharmacy staff about the study and interviewed the technicians who used the system. The study was presented as a test of the system in the pharmacy and not as an obligation. Even if barriers are overcame and a system is implemented, new risks may appear, and the requirement of 
workarounds described for BCMA systems should not be underestimated. ${ }^{30-32}$

This study had some limitations due to the study design and the technology itself. The study was conducted over 6 days with two technicians supervising the use of the system by four technicians dedicated to unit-dose dispensing. There may have been contamination bias, as the four technicians worked in the same room, but the aim of our study was to validate the system and not to consider such bias. Due to the complexity of the observation method and the availability of the BCMA system, only two wards were tested using the system. Nevertheless, it should have been interesting to investigate the two other wards as experimental ward to have exhaustive observations. We did not investigate the actual time required to dispense drugs using the BCMA system. However, the perception of the pharmacy technicians was that it was time consuming, as previously quantified by Samaranayake et al. ${ }^{22}$ Using a standardized survey, Holden et al reported little efficacy in improving either personal job performance or patient care. ${ }^{33}$ In our study, the two technicians who used the system found it globally easy to use, but did not find that it improved work performance. A major limitation is the integration of the system to the EHR that was not possible at the beginning of the study.

\section{Conclusion}

This study highlights the difficulties of integrating a commercial system to a current HIS. Technical issues (such as interoperability interfaces, lack of unit-dose barcodes), structural, workforce, and strategic issues need to be taken into consideration before the development of a BCMA system in a teaching hospital. In our experience, integration of this system into the EHR is the key for the success of this process with an entire closed loop system from prescription to administration. BCMA system at the dispensing process remains essential to purchase securing medication administration process.

\section{Clinical Relevance Statement}

Use of these systems at the pharmacy for dispensing drugs is rare. Technical, structural, work force, and strategic issues need to be taken into consideration before the integration of a commercial BCMA system. Semantic interoperability is a critical barrier to the integration and use of a commercial BCMA system in a teaching hospital.

\section{Multiple Choice Questions}

1. Which factor is identified as error-provoking conditions that influence administration errors?
a. Dispensing step.
b. Pharmaceutical analysis.
c. Double checking before administration.
d. Medical and nurse staff.

Correct Answer: The correct answer is option a. Keers et al identified error-provoking conditions that influence administration errors. ${ }^{4}$ The authors found that administration errors appeared to be associated with errors that occurred earlier in the medication process, during pharmacy dispensing, and ward stock management.,

2. When implementing a BCMA system at the pharmacy, which of the following must have close attention to avoid difficulties in implementation?

a. Nurses transmission.

b. Interoperability interfaces.

c. Pharmaceutical analysis.

d. Long staff training.

Correct Answer: The correct answer is option b. The interoperability interfaces used during this study were based on files generated by database triggers. These files contain the data required elements, structured according to the corresponding standard. In our opinion, file-based interoperability interfaces should be, avoided, because the generated files necessitated management of the disk space in which files are stored. In addition, files can be lost, deleted, or corrupted.

\section{Protection of Human and Animal Subjects}

This study was conducted as part of the protocol DREAM (NCT02325336). Human research ethics approval was received from CPP-Ile-de-France in November 2013 (ID RCB: 2013-A01101-44).

\section{Funding}

This work was supported by the French National Institute of Health (Direction Générale de l'Offre de Soins -DGOS) as the "Programme de Recherche sur la Performance du Système de Soin” (PREPS) 2012 (number PHRQ1034).

\section{Conflict of Interest}

None declared.

\section{Acknowledgments}

The authors thank Béatrice Dejean (senior pharmacy technician), Nathalie Valin (senior pharmacy technician manager), and the four pharmacy technicians for their participation in the study.

\section{References}

1 Keers RN, Williams SD, Cooke J, Ashcroft DM. Prevalence and nature of medication administration errors in health care settings: a systematic review of direct observational evidence. Ann Pharmacother 2013;47(02):237-256

2 Berdot S, Gillaizeau F, Caruba T, Prognon P, Durieux P, Sabatier B. Drug administration errors in hospital inpatients: a systematic review. PLoS One 2013;8(06):e68856

3 Poon EG, Keohane CA, Yoon CS, et al. Effect of bar-code technology on the safety of medication administration. N Engl J Med 2010; 362(18):1698-1707

4 Keers RN, Williams SD, Cooke J, Ashcroft DM. Causes of medication administration errors in hospitals: a systematic review of quantitative and qualitative evidence. Drug Saf 2013;36(11):1045-1067

5 Beso A, Franklin BD, Barber N. The frequency and potential causes of dispensing errors in a hospital pharmacy. Pharm World Sci 2005;27(03):182-190 
6 Cina JL, Gandhi TK, Churchill W, et al. How many hospital pharmacy medication dispensing errors go undetected? Jt Comm J Qual Patient Saf 2006;32(02):73-80

7 Allan EL, Barker KN. Fundamentals of medication error research. Am J Hosp Pharm 1990;47(03):555-571

8 Hicks RW, Cousins DD, Williams RL. Selected medication-error data from USP's MEDMARX program for 2002. Am J Health Syst Pharm 2004;61(10):993-1000

9 Agence Française de Sécurité Sanitaire des produits de Santé (ANSM). Le Guichet Erreurs Médicamenteuses: Bilan d'activité de l'année 2009; 2010

10 Fox BI, Pedersen CA, Gumpper KF. ASHP national survey on informatics: assessment of the adoption and use of pharmacy informatics in U.S. hospitals-2013. Am J Health Syst Pharm 2015; 72(08):636-655

$11 \mathrm{~T} \mathrm{H}$, Heelon M, Siano B, et al. Medication safety improves after implementation of positive patient identification. Appl Clin Inform 2010;1(03):213-220

12 Pedersen CA, Schneider PJ, Scheckelhoff DJ. ASHP national survey of pharmacy practice in hospital settings: dispensing and administration-2002. Am J Health Syst Pharm 2003;60(01):52-68

13 Pedersen CA, Schneider PJ, Scheckelhoff DJ. ASHP national survey of pharmacy practice in hospital settings: prescribing and transcribing-2016. Am J Health Syst Pharm 2017;74(17):1336-1352

14 Poon EG, Cina JL, Churchill W, et al. Medication dispensing errors and potential adverse drug events before and after implementing bar code technology in the pharmacy. Ann Intern Med 2006;145 (06):426-434

15 Barker KN, McConnell WE. The problems of detecting medication errors in hospitals. Am J Hosp Pharm 1962;19:361-369

16 Flynn EA, Barker KN, Pepper GA, Bates DW, Mikeal RL. Comparison of methods for detecting medication errors in 36 hospitals and skillednursing facilities. Am J Health Syst Pharm 2002;59(05):436-446

17 Fleiss JL. Measuring nominal scale agreement among many raters. Psychol Bull 1971;76:378-382

18 Allan BL. Calculating medication error rates. Am J Hosp Pharm 1987;44(05):1044-1046

19 ASHP guidelines on preventing medication errors in hospitals. Am J Hosp Pharm 1993;50(02):305-314

20 Siska MH, Tribble DA. Opportunities and challenges related to technology in supporting optimal pharmacy practice models in hospitals and health systems. Am J Health Syst Pharm 2011;68 (12):1116-1126

21 Phast - Information de santé standardisée (CIO - PN13 - MIO). Available at: http://www.phast.fr/about-phast-2/. Accessed July 19, 2019

22 Samaranayake NR, Cheung STD, Cheng K, Lai K, Chui WCM, Cheung BMY. Implementing a bar-code assisted medication administration system: effects on the dispensing process and user perceptions. Int $\mathrm{J}$ Med Inform 2014;83(06):450-458

23 Koppel R, Metlay JP, Cohen A, et al. Role of computerized physician order entry systems in facilitating medication errors. JAMA 2005; 293(10):1197-1203

24 Using Resources with Services and Service-oriented Architecture. Available at: https://www.hl7.org/fhir/services.html. Accessed July 19, 2019

25 Saleem JJ, Russ AL, Sanderson P, Johnson TR, Zhang J, Sittig DF. Current challenges and opportunities for better integration of human factors research with development of clinical information systems. Yearb Med Inform 2009:48-58

26 Zachariah M, Phansalkar S, Seidling HM, et al. Development and preliminary evidence for the validity of an instrument assessing implementation of human-factors principles in medication-related decision-support systems-I-MeDeSA. J Am Med Inform Assoc 2011;18(Suppl 1):i62-i72

27 Phansalkar S, Edworthy J, Hellier E, et al. A review of human factors principles for the design and implementation of medication safety alerts in clinical information systems. J Am Med Inform Assoc 2010;17(05):493-501

28 Klein K, Stolk P. Challenges and opportunities for the traceability of (biological) medicinal products. Drug Saf 2018;41(10):911-918

29 Nanji KC, Cina J, Patel N, Churchill W, Gandhi TK, Poon EG. Overcoming barriers to the implementation of a pharmacy bar code scanning system for medication dispensing: a case study. J Am Med Inform Assoc 2009;16(05):645-650

30 Koppel R, Wetterneck T, Telles JL, Karsh BT. Workarounds to barcode medication administration systems: their occurrences, causes, and threats to patient safety. J Am Med Inform Assoc 2008; 15(04):408-423

31 Van der Veen W, van den Bemt PMLA, Wouters H, et al. Association between workarounds and medication administration errors in bar-code-assisted medication administration in hospitals. J Am Med Inform Assoc 2018;25(04):385-392

32 Wang J, Liang H, Kang H, Gong Y. Understanding health information technology induced medication safety events by two conceptual frameworks. Appl Clin Inform 2019;10(01):158-167

33 Holden RJ, Brown RL, Scanlon MC, Karsh B-T. Pharmacy workers' perceptions and acceptance of bar-coded medication technology in a pediatric hospital. Res Social Adm Pharm 2012;8(06): 509-522

34 Boussadi A, Bousquet C, Sabatier B, Caruba T, Durieux P, Degoulet P. A business rules design framework for a pharmaceutical validation and alert system. Methods Inf Med 2011;50(01): $36-50$

35 Boehm B, Abts C, Brown A, et al. Software Cost Estimation with COCOMO II. Upper Saddle River, NJ: Pearson Education(US); 2009 